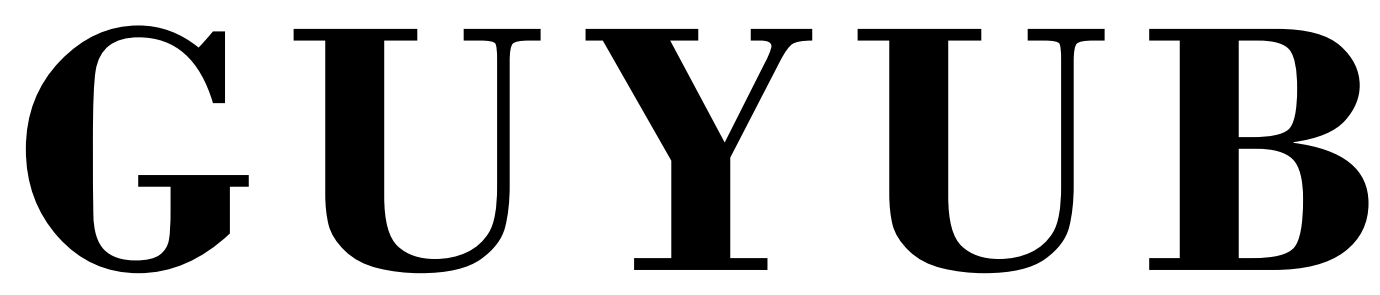

Journal of Community Engagement

Vol. 2, No. 2, Agustus 2021

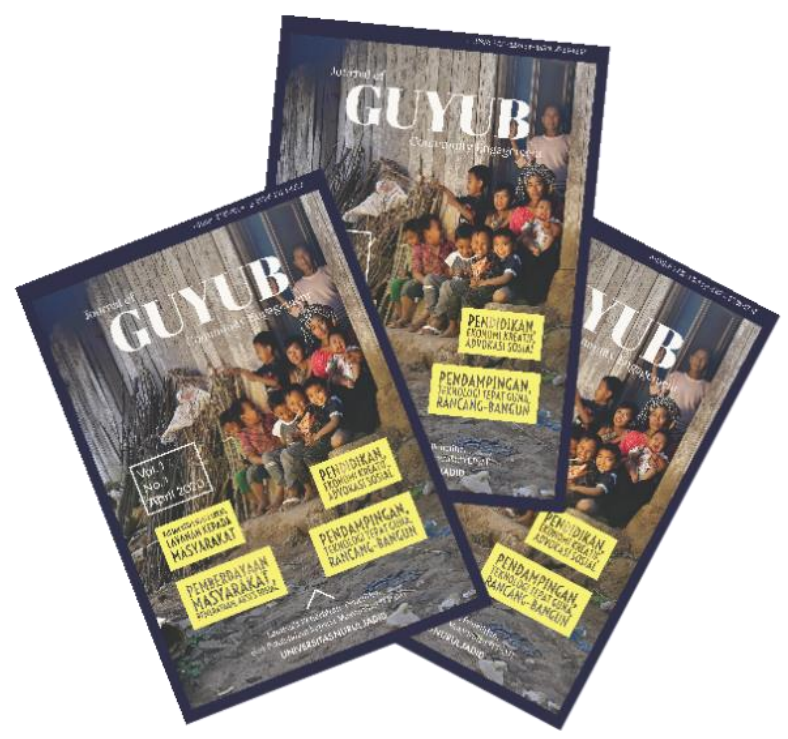

PKM Pendampingan Santri Nurul Jadid melalui Gerakan Literasi Cerdas dalam Membentuk Komunitas Pelajar Berkarakter Islam di Pondok Pesantren Nurul Jadid

Faizatul Widat, Afita Khoirun Nisa', Wardatul Habibah, Wahibatul Mas'ula, Nikmatul Hosniah, Jamilatul Masnunah, Hamidah

PKM Penyuluhan Pembuatan dan Penyemprotan Disinfektan (PEPEDES) sebagai Upaya Pencegahan Covid-19 di Desa Kalikajar Kulon Probolinggo

Fahrudin, Ayu Midyah Putri, Abdul Hamid Isnaini, Abdul Latif Isnaini, Duwi Handika Okta Rotama, Rosi Nurjannah, Suharno

PKM Pendampingan Penyusunan Kurikulum Sekolah Ramah Anak pada Taman Kanak Kanak (TK) Az-Zainiyah II Paiton Probolinggo

Abu Hasan Agus R, Durratul Mashunah, Hostin, Hilyah Mashunah, Siti Rahayu, Atik Hikmatuz Zakiyah 


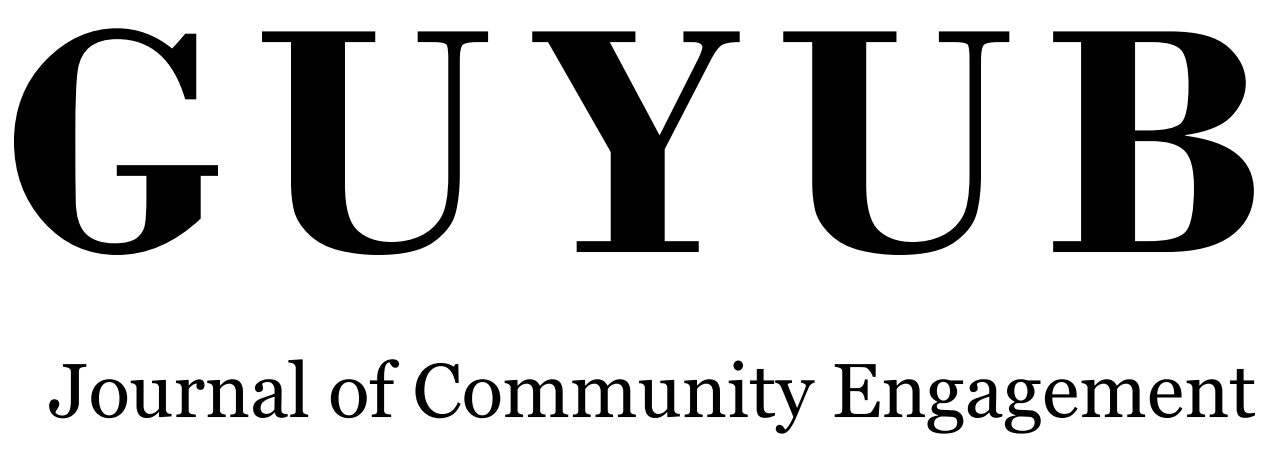




\section{G U Y U B}

\section{Journal of Community Engagement}

Vol. 2, No. 2, 2021

\section{Editor in Chief}

Achmad Fawaid, (SCOPUS ID: 57214837323)

\section{Managing Editors}

Hasan Baharun, (ID SCOPUS : 57200983602)

Sugiono Sugiono, (SCOPUS ID : 57199578160)

Ismail Marzuki, (SCOPUS ID: 57201500245

Subhan Rachman, (SCOPUS ID: 57192937912)

Nurul Huda, (SINTA ID: 6119615)

Syamsuri, (SINTA ID: 6116825)

Ridhatullah Assya'bani, (SINTA ID: 6200862)

\section{Peer Reviewers}

Miftahul Huda, (SINTA ID: 6171566), University of Antwerp, Belgium Achmad Naufal Irsyadi (SINTA ID: 6704870), Universitas Nurul Jadid, Indonesia Sukamto Sukamto, (SINTA ID: 5979034), Universitas Widya Gama Malang, Indonesia Deny Utomo, (SINTA ID: 6016108), Universitas Yudharta Pasuruan, Indonesia Fariz Alnizar, (SCOPUS ID: 6659824), UNUSIA Jakarta, Indonesia Fuad Rahman, (SCOPUS ID: 57201474778), UIN Sulthan Thaha Saifuddin Jambi, Indonesia Saifuddin Zuhri Qudsy, (SCOPUS ID: 57213595165), UIN Sunan Kalijaga Yogyakarta, Indonesia Akhmad Anwar Dani, (SINTA ID: 14305), IAIN Surakarta, Indonesia Maufur Maufur, (SINTA ID: 5989329), IAIN Kediri, Indonesia Siti Mahmudah Noorhayati, (SINTA ID: 6726997), IAIN La Roiba Bogor, Indonesia Busro Busro, (SCOPUS ID: 57205022652), UIN Sunan Gunung Djati Bandung, Indonesia Akmal Mundiri, (SCOPUS ID: 57205059378), UNUJA Probolinggo, Indonesia

\section{Section Editor}

Ahmad Zubaidi, Universitas Nurul Jadid, Probolinggo, Indonesia 
GUYUB: Journal of Community Engagement is a multidisciplinary journal which aims to disseminate the conceptual thoughts and research results in the area of community service. This journal focuses on the main problems of the community engagement areas, such as (1) training, marketing, appropriate technology, design; (2) student community services; (3) community empowerment, social access; (4) education for sustainable development, etc.

GUYUB: Journal of Community Engagement is published three times a year (April, August, December) by Lembaga Penerbitan, Penelitian, dan Pengabdian kepada Masyarakat (LP3M) Universitas Nurul Jadid, Paiton, Probolinggo, Jawa Timur, Indonesia.

Editorial Office:

GUYUB: Journal of Community Engagement

Lembaga Penerbitan, Penelitian, dan Pengabdian kepada Masyarakat (LP3M) Universitas Nurul Jadid, Paiton, Probolinggo, Jawa Timur, Indonesia 67291.

Phone: 088830 77077, Hp: 082318007953

Email: jurnal.guyub@gmail.com

Website: https://ejournal.unuja.ac.id/index.php/guyub/index 


\section{Tables of Content}

178-191

PKM Pendampingan Santri Nurul Jadid melalui Gerakan Literasi Cerdas dalam Membentuk Komunitas Pelajar Berkarakter Islam di Pondok Pesantren Nurul Jadid

Faizatul Widat, Afita Khoirun Nisa', Wardatul Habibah, Wahibatul Mas'ula, Nikmatul Hosniah, Jamilatul Masnunah, Hamidah

192-201

PKM Pelatihan Deep-Listening untuk Meningkatkan Kemampuan Berbahasa Inggris Santri Nurul Jadid Durratul Hikmah, Taufiqur Rahman, Irfan Wahyudi, Nur Hayati, Ahmad Zainullah, Kuni Zakiya Maskuroh

$202-210$

PKM Pendampingan Speaking Skill dengan Metode TROPIG di Wilayah Al Hasyimiyah Pondok Pesantren Nurul Jadid

Syaiful Islam, Nur Azizah, Rifdatul Qomariyah, Anis Fitria, Nurul Hamidah, Masrufah Masrufah

\section{1-224}

PKM Penyuluhan Pembuatan dan Penyemprotan Disinfektan (PEPEDES) sebagai Upaya Pencegahan Covid-19 di Desa Kalikajar Kulon Probolinggo

Fahrudin, Ayu Midyah Putri, Abdul Hamid Isnaini, Abdul Latif Isnaini, Duwi Handika Okta Rotama, Rosi Nurjannah, Suharno

225-232

PKM Pelatihan Pengisian Pengajuan Izin Operasional Taman Pendidikan Al-Quran secara Online Moh Jasri, Muhammad Romdloni, Mohammad Akmalor Riski, Nurul Hidayatullah, Muhammad Hasan Andika, Yogi Angga Praditya, Syukron Khafi, Shancen Ammabiel

\section{3-249}

PKM Pelatihan Pemanfaatan E-Learning Berbasis Teknologi Berbasis Platform Google Classroom bagi Guru Madrasah Ibtidaiyah Nurul Mun'im (MINM) Paiton Probolinggo

Feriska Listrianti, Nur Ika Sari, Siti Khomariya, Huswatun Hasanah, Millatun Hanifah, Deviyatul Hasanah

250-264

PKM Pelatihan Tutor Lembaga Kebahasaan Az-Zainiyah melalui Game Islami untuk Meningkatkan Keterampilan Berbicara Bahasa Inggris

Bradhiansyah Tri Suryanto, Nur Hasanah, Nuril Diar Anas, Sri Waliyul Hasanah, Syaiful Syaiful, Lia Umami

\section{5-275}

PKM Deteksi Dini Kelainan Tumbuh Kembang dengan Skrining Denver II dan Health Education di Taman Pendidikan Anak Shaleh Nurul Jadid Paiton Probolinggo

Zainal Munir, Zainul Hasan, Siti Nur Kholishoh, Melinia Akhirul Fitri 
PKM Habituasi Nilai-Nilai Keagamaan melalui Kegiatan Rohani DITABERHAMAN dalam Menciptakan Kesalehan Sosial di Pondok Mahasiswi (POMASI) Nurul Jadid Paiton Probolinggo

Zakiyah BZ, Ana Muthmainnah, Aminatuz Zuhriyah, Hamidah Hamidah, Miftahul Jannah, Wardatus Sholihah, Elok Nafiqoh

293-302

PKM Diversifikasi Ragam Produk Olahan Berbahan Dasar Ikan Teri sebagai Upaya Peningkatan Ekonomi Masyarakat Paiton Probolinggo

Saifuddin, Andre Dimas Fernando Putra, Moch Sofyan, Fadhlur Rohman, Mohammad Hasan Ainul Yaqin, Nailis Saadah Ali

303-312

PKM Pendampingan Penyusunan Kurikulum Sekolah Ramah Anak pada Taman Kanak Kanak (TK) AzZainiyah II Paiton Probolinggo

Abu Hasan Agus R, Durratul Mashunah, Hostin Hostin, Hilyah Mashunah, Siti Rahayu, Atik Hikmatuz Zakiyah

\section{3-325}

PKM Pelaksanaan Kegiatan Ekstrakurikuler Keagamaan dalam Membangun dan Mengembangkan Bakat dan Minat Santri pada Bidang Keagamaan di Madrasah Tsanawiyah (MTs) Nurul Jadid Probolinggo

Abdullah, Habibaturrohmah Habibaturrohmah, Halimatus Sakdiyah, Aisyah Amini, Putri Yunita Sari, Lilis Sulistiawati, Fitriyatun

326-341

PKM Sosialisasi Aplikasi Edmodo sebagai Alternatif Media Pembelajaran Daring di Madrasah Ibtidaiyah (MI) Az-Zainiyah II Paiton Probolinggo

Niken Septantiningtyas, Suhairiyah Suhairiyah, Fadilatul Hasanah, Umatuz Sholihah

$342-350$

PKM Pendampingan Pelatihan Penulisan Karya Tulis IImiah dalam Meningkatkan Kompetensi Guru di Madrasah Tsanawiyah (MTs) Nurul Jadid Paiton Probolinggo

Musolli Ready, Moh. Amir Kholili, Moh. Abd Mu'iz, Jefri Jefri, Moh. Agus, Moh. Ridwan Kamil

$351-360$

PKM Literasi Penguatan 3-M (Memakai Masker, Mencuci Tangan, dan Menjaga Jarak) Melalui Metode Storytelling di Pondok Pesantren Nurul Jadid Probolinggo

Mohammad Sofyan Adi, Dina Nur Faizah, Kamelia Yulia Novita, Robiatul Adawiyah, Ulfatul Nimatillah, Nuriah Waizul Romdani

361-368

PKM Pendampingan Pembelajaran Materi Bangun Datar dengan Billingual LED Running Text di Madrasah Ibtidaiyah (MI) Az-Zainiyah II Paiton Probolinggo

Nur Hamid, Muhammad Faiz Nailun Ni'am, Cahyu Guswita, Saiful Islam, Silviana Qomariyah, Siti Fatimah, Siti Khoifah

369-383

PKM Pendampingan Literasi Business Plan untuk Meningkatkan Pengetahuan dan Keterampilan Berwirausaha Santri Pesantren Nurul Jadid Mohammad Syaiful Suib, Yoviana Fitri, Lailatus Sa'adah, Nuril Fitriani, Widad Ulfatul Mawaddah Hadi, Siti Aisyah, Isna Shifah 
384-403

PKM Penanaman Karakter Berbasis Keagamaan bagi Warga Binaan Rumah Tahanan Kelas II. B Kraksaan Probolinggo Jawa Timur

Ahmad Fawaid, Muhammad Zaimul Millah, Achmad Naufal Baidawi, Siti Arofah, Nur Khofifah, Elmiyatus Soliha, Syukron Jazila, Rif'ah Hasanah, M Zainuddin

404-416

PKM Pendampingan Menghafal Al-Quran dengan Metode An-Nur pada Siswa Kelas X IPA Tahfidz Madrasah Aliyah Nurul Jadid Paiton Probolinggo

Abdurrahman, Indriani Putri Ayu Lestari, Lailia Mutmainnah, Hakimatus Sailah, Ika Fitri Anwar, Sofiya Mauliza, Nadya Afkarina

417-423

PKM Peningkatan Pendapatan pada Bidang Keputrian Wilayah Az-Zainiyah Pondok Pesantren Nurul Jadid melalui Strategi Pemasaran Berbasis Web

Anis Yusrotun Nadhiroh, Dina Wahyuni Suciati, Dzurrotun Nafila, Eva Nurmaliya, Nabila Maulidir Roziqina Fara 


\title{
PKM Habituasi Nilai-Nilai Keagamaan melalui Kegiatan Rohani DITABERHAMAN dalam Menciptakan Kesalehan Sosial di Pondok Mahasiswi (POMASI) Nurul Jadid Paiton Probolinggo
}

\author{
Zakiyah BZ ${ }^{1}$, Ana Muthmainnah², Aminatuz Zuhriyah ${ }^{3}$, Hamidah4, \\ Miftahul Jannah ${ }^{5}$, Wardatus Sholihah ${ }^{6}$, Elok Nafiqoh ${ }^{7}$ \\ Universitas Nurul Jadid 1,2,3,4,5,6,7 \\ $\underline{\text { \{emailauthor@institution.ac.id }}{ }^{1}$, emailauthor@institution.ac.id ${ }^{2}$, \\ emailauthor@institution.ac.id $\left.{ }^{3}\right\}$
}

Submission: 2021-06-07 Received: 2021-08-18 Published: 2021-08-31

\section{Keywords: \\ Habituation, \\ Religious Culture, Teenager's Social Distraction, Spiritual Healthy Milleneal}

\begin{abstract}
This article discussed the habituation of cultural religious values in the construction of adolescent social transitions in islamic boarding schools through healthy spiritual activities at Nurul Jadid Paiton Islamic Boarding School Probolinggo. At the end of 2019, the world was shocked by the Covid 19 pandemic and became an international issue that paralyzed the joints of world stability, especially in the world of higher education. The closure of face-toface educational spaces had an impact on millions of students. Some of the effects of the Covid 19 pandemic in universities was a change in the learning system, increased use of technology and student learning independence. Disturbances in the face-to-face learning process between students and lecturers, students and teachers at school as well as restrictions on the assessment of learning experiences had an impact on the development of social intelligence and psychological health and reduce the quality of student skills. Students, especially santri as milleneal generation, must be responsive and innovative in facing some of these obstacles. This innovation was carried out by university students Nurul Jadid by holding activities to habituate religious culture values as a way to construct students' social distraction which is packaged through the healthy spiritual activities of DITABERHAMAN milleneal. This activity was carried out every week so that students' spiritual and social skills are maintained and awake during this pandemic.
\end{abstract}


Katakunci:

Habituasi, Kesalehan Sosial Ditaberhaman, Kegiatan Rohani, POMASI

\begin{abstract}
Abstrak. Artikel ini menguraikan pelaksanaan pengabdian kepada masyarakat melalui pembiasaan (habituasi) nilai-nilai kegamaan melalui kegiatan rohani sehat milenial. Salah satu upaya pengabdian yang dilakukan adalah pelaksanaan kegiatan pembacaan DITABERHAMAN (Diba'iyah, Tahlil, Berzanji, Hataman Qur'an, Manaqib). Partisipan pengabdian adalah para mahasiswi di Asrama Pondok Mahasiswi (POMASI) Pondok Pesantren Nurul Jadid Paiton Probolinggo. Hasil PKM ini meningkatnya kemampuan mahasiswi POMASI dalam memimpin bacaan DITABERHAMAN dan menghayati isi yang terkandung pada bacaan tersebu. Kegiatan PKM berbasis keshalehan ritual ini dapat menciptakan dan mengkonstruksi keshalehan sosial mereka.
\end{abstract}

\section{Pendahuluan}

Remaja dan permasalahannya merupakan topik pembicaraan yang menarik dan tidak akan pernah ada habisnya. Hal ini dikarenakan pada masa remaja terjadi perubahan sosial sekaligus dan psikologis yang memungkinkan terjadi integrasi pada kepribadian remaja seperti terbentuknya perasaan inkonsistensi dalam kehidupannya, adanya sikap identitas peran, sehingga terkadang membingungkan bagi remaja itu sendiri. Tidak jarang remaja memiliki masalah berikut ini seperti skeptis, hipokrit bahkan masalah ediologi dan keyakinan yang mereka pilih seperti pada pandangan ketuhanannya yang menjadi kacau karena beragamnya aliran paham yang saling bertentangan, penghayatan pengalaman rohani yang selama ini diperolehnya. Dari masalah remaja yang beragam dan komplek ini maka di perlukan model pendidikan yang tepat untuk membantu siswa agar memiliki kesalehan sosial yang baik agar mampu melewati masa remajanya yang bermakna untuk memasuki fase perkembangan berikutnya.

Pendidikan merupakan salah satu proses pembentukan kemampuan fundamental secara intelektual dan emosional kepada sesama manusia dan lingkungannya. Pendidikan adalah elemen penting dalam membangun suatu bangsa, dapat di artikan bahwa kualitas pendidikan mencerminkan kualitas suatu bangsa (Mannuhung, 2019). Salah satu masalah mendasar yang sering di hadapi pendidik dalam dunia pendidikan adalah perilaku dan moralitas siswa yang di didiknya.

Sekolah merupakan lembaga pendidikan utama bagi manusia khususnya di usia remaja. Sebagian besar orang tua mempercayakan pendidikan anak 
mereka untuk di didik dan dibimbing di sekolah. Oleh karena itu sekolah sangat perlu di laksanakan, Orang tua mengharapkan anaknya bisa menjadi cerdas dan berakhlak mulia setelah masuk sekolah.[4] Proses pendidikan diharapkan dapat mewujudkan suasana belajar peserta didik secara aktif dan efektif untuk mengembangkan potensi dirinya dan untuk memiliki kecerdasan spiritual keagamaan, kecerdasan intelektual, emosional dan pengendalian diri, akhlak mulia serta keterampilan yang di perlukan dirinya, sebagai bagian dari masyarakat dan warga negara (Mannuhung, 2019). Namun pada kenyataannya, sekolah pada umumnya hanya dapat mencetak siswa menjadi cerdas dan pintar akan tetapi tidak berkarakter. Hal tersebut dikarenakan sekolah hanya mengedepankan aspek kognitif siswa dan mengesampingkan penanaman nilai-nilai agama pada pendidikan siswa. Minimnya penanaman nilai-nilai agama tersebut menyebabkan kondisi moral siswa semakin memprihatinkan (Qodriyah \& Bz, 2020).

Menyikapi banyaknya perilaku menyimpang di kalangan pelajar, banyak dari orang tua lebih memasrahkan dan mempercayakan anak mereka untuk mendapatkan pendidikan dan ilmu agama di pesantren. Pesantren dalam bentuknya tidak dapat di samakan dengan pendidikan sekolah yang di kenal pada umumnya. Demikian pula, tidak ada kesatuan bentuk dan cara yang berlaku bagi semua pesantren, melainkan hal ini sudah ditentukan oleh pengasuh pesantren yang sering dikenal "kiai" dan pemegang pimpinan pesantren. Serta ditentukan oleh masyarakat lingkungannya yang menjadi pendukung pesantrenn (Saifuddin, n.d.).

Pesantren sebagai suatu lembaga yang tumbuh dan berkembang di tengah-tengah masyarakat sekaligus memadukan tiga unsur penting, yaitu: ibadah untuk menanamkan iman, tabligh untuk penyebaran ilmu, dan amal untuk mewujudkan kegiatan kemasyarakatan dalam kehidupan sehari-hari (Kholid Junaidi, 2016). Pendidikan pesantren yang bersifat boarding memungkinkan internalisasi nilai-nilai Islam dapat di lakukan secara maksimal sehingga dapat di bentuk budaya dan kebiasaan religius yang dapat mencegah santri melakukan perbuatan-perbuatan menyimpang (Studi et al., 2019).

Pesantren sangat berperan dalam mengatasi kenakalan remaja, dikarenakan nilai-nilai Islam yang di tanamkan kepada santri dituntut untuk dipraktikkan dalam kehidupan sehari-hari. Dengan kebiasaan yang di 
tanamkan tersebut santri lebih dapat berpikir rasional dan mampu membedakan mana hal yang baik dan mana hal yang buruk. Nilai-nilai budaya keagamaan penting diwujudkan dalam penerapan program pembiasaan yang kemudian menjadi karakter. Nilai-nilai inilah nantinya sebagai output dari segala pelaksanaan pembelajaran dan budaya dipesantren. Nilai-nilai tersebut meliputi komponen pengetahuan, kesadaran, dan kemauan, tindakan untuk melaksanakan nilai-nilai tersebut, baik untuk Tuhan Yang Maha Esa, diri sendiri, sesama, lingkungan, maupun kebangsaan, sehingga menjadi manusia insan kamil. Usaha yang dapat di lakukan untuk membangun karakter bangsa adalah melalui penguatan karakter bangsa, aktualisasi nilai-nilai luhur Pancasila, implementasi ajaran-ajaran agama dalam kehidupan sehari-hari, keteladanan dari komponen bangsa, dan melalui pendidikan formal maupun pendidikan non formal (F. Pendidikan, 2015).

Nilai-nilai agama harus ditanamkan sejak dini kepada anak-anak di mana pun mereka berad. Anak-anak adalah bagian dari masa kini dan keseluruhan di hari esok. Mereka adalah penerus yang akan mengambil alih tampuk kepemimpinan dan tanggung jawab kendali bangsa negara agama di masa depan. Di tangan merekalah nasib bangsa, negara, dan agama di pertaruhkan. Dalam Islam di perintahkan untuk menyeimbangkan antara habblum minallah dan habblum minannas, agar supaya kehidupan manusia dapat seimbang (Kunci et al., n.d.).

Dengan demikian, orang yang rajin beribadah disebut sebagai orang yang saleh dan kesalehan dalam konsep Islam berbentuk tindakan yang berguna bagi diri pribadi dan orang lain atas dasar ketundukan pada ajaran Islam, bahkan tindakan saleh merupakan hasil pernyataan iman seseorang yang dilakukan secara sadar atas ajaran Allah SWT. Dalam kerangka membangun katakter terdapat beberapa aspek yang harus terlibat yaitu: aspek religius dan aspek kesalihan ritual yang menjadi salah satu faktor agar kesalihan sosial terbangun dan perlu ditanamkan secara maksimal, karena nilai budaya religius adalah salah satu pembentuk karakter. Penanaman budaya religius ini menjadi tanggung jawab orang tua dan lembaga pendidikan yang mereka pilih, dalam ini adalah pesantren. Yang bertujuan melalui penanaman nilai nilai religious culture/buadaya religius yang dilaksanakan dipesantren bisa 
menjadi fondasi dalam membangun kesalihan sosial hamasiswi yang ada di asrama POMASI; Pondok pesantren Nurul JAdid Paiton Probolinggo.

\section{Metode}

\section{Strategi Pelaksanaan}

Strategi pelaksanaan kegiatan pendampingan dan pengabdian masyarakat ini dilakukan melalui habituasi nilai-nilai religious culture dalam kontruksi kesalihan sosial remaja di pesantren melalui kegiatan DITABERHAMAN (Pembacaan Diba'iyah, Tahlil, Berzanji, Hataman Qur'an, Manaqib) (1) yang dikemas dalam kegiatan di asrama mahasiswi (POMASI). Pengabdian dilakukan Melalui pendekatan (1) Power Strategy komunikasi dengan musyawarah pengurus pesantren (POMASI) Universitas Nurul Jadid di Pesantren Nurul Jadid yang terdiri dari kepala bidang pondok mahasiswi, kepala pesantren, pengurus pesantren bagian ubudiyah. (2) persuasive strategy, yang diimplementasikan lewat pendekatan persuasif oleh pelaksana pengabdian kepada santri sebagai remaja yang berdomisili di pesantren. melalui komunikasi yang efektif, pembentukan opini dan pelaksaan program kegiatan pengabdian yang di kemas dalam istilah DITABERHAMAN (3) normative re-educative, dengan pembiasaan nilai-nilai budaya keagaaan (religious culture) yang terdapat pada kegiatan keagamaan DUTABERHAMAN tersebut.

\section{Gambaran Umum Lokasi Pendampingan}

Lembaga pendidikan tinggi pesantren nurul jadid adalah Universitas Nurul Jadid. Yang mayoritas mahasiswanya adalah santri pondok pesantren Nurul jadid, sehingga universitas memiliki peran yang utuh untuk melahirkan output mahasantri yang tetap menjaga kearifan lokal yang ada di pesantren dan menciptakan suasana kampus yang berkeadaban sesuai dengan visi misi unuversitas, sehingga ada pengintegrasian antara peraturan pondok pesantren dan universitas.

Sebagai perguruan tinggi yang ada di naungan pesantren, Universitas Nurul Jadid tidak hanya mampu melahirkan output yang mampu dan cakap dalam melaksanakan tridarma perguruan tinggi saja. Namun yang menjadi 
sangat peting adalah bagaimana mahasantri memiliki kesalihan sosial yang bermula dari kesalihan ritual atau pratik melalui budaya keagamaan (Religius culture), kecerdasan dan kemampuan untuk menggali potensi yang mereka miliki.

Sebagai manusia pada umumnya, mereka memiliki potensi yang harus berkembang sesuai dengan fasenya, disisi lain mahasiswi sebagai remaja dan pelajar yang ada dipesantren juga harus bisa berperilaku akhlaki yang sesuai dengan trilogi dan panca kesadaran santri pondok pesantren Nurul Jadid yang kemudian menjadi ciri khas dan jati diri santri sebagai mahasiswa yang berada dibawah naungan pesantren Nurul Jadid. Sehingga cita-cita ingin melahirkan ouput yang berkearifan lokalpun akan terwujud dan beberapa keinginan luhur pesantren dan universitas ini terlaksana. Dengan demikian perlu adanya stimulus yang bisa mengarah pada pembinaan dalam meningkatkan piramida belajar dan pembinaan akhlak mahasantri.

\section{Kondisi Masyarakat Dampingan Saat Ini}

Fakta dan Data menunjukan bahwa terdapat mahasasiswa di pesantren Nurul Jadid yang belum terbiasa dengan kebiasaan dan budaya pesantren terutama dengan kebudayaan praktik keagamaan, etika maupun estetika, serta terdapat perilaku santri yang tidak akhlaki yang tidak relevan dengan cita-cita luhur pesantren, termasuk beberapa santri pondok mahasiswi (POMASI). mereka yang belum memiliki kompetensi kesalihan ritual yang akan menjadi embrio terbentukya kesalihan sosial santri tersebut, baik mahasiswa baru maupun beberapa mahasiswa lulusan yang melanjutkan kejenjang universitas di pesantren. mereka yang belum bisa dan cakap dalam ilmu fardhu a'in dan baca tulis al-Qur'an diberikan pembinaan khusus dari pesantren. Dalam hal ini universitas melalui lembaga integrasi kokurikuler bidang pondok mahasiswi (POMASI) sedang melaksanakan integrasi kurikulum keagaan dengan pesantren.

Universitas Nurul Jadid melalui lembaga integrasi kokurikuler (LIK) bidang pondok mahasiswi (POMASI) merasa memiliki tanggung jawab besar untuk melahirkan output perguruan tinggi yang bisa dan cakap dalam melaksanakan tridarma perguruan tinngi juga mampu melahirkan output mahasanrti yang berkearifan lokal berkebangsaan berkeadaban sesuai dengan visi misi 
universitas Nurul Jadid dan cita-cita luhur pesantren yang tertuang dalam trilogi dan panca kesadaran santri.

\section{Kondisi yang Diharapkan}

Kondisi yang diharapkan adalah pertama mahasiswa sebagai remaja yang ada dipesantren mereka harus membiasakan diri dengan kegiatan keagamaan yang sudah menjadi budaya keislamaan di pesantren yang nantinya bisa di amlkan di masyrakat ketika mereka sudah pulang kerumah masing-masing. Kedua mahasiswa diharapkan bisa menjadi role model dalam hal kegiatan keagamaan yang ada di masyarakatnya Ketika pulang nanti. Ketiga melatih mahasiswa yang ada di pesantren untuk tidak deman panggung Ketika ada di tengah-tengah masyarakat apabila di suruh untuk memimpin dan memebaca budaya tahlilan, budaya pembacaan diba'iyah, terutama pada saat maulid Nabi, budaya pembacaan diba'iyah sangat di junjung tinggi dan hampir setiap hari di alntunkan di seluruh Indonesia khususnya di pesantren-pesantren yang berbaisi NU dan Muhammadiyah dan manaqiban dan lain sebagainya. Kegiatan pengabdian masyarakat yang dijalankan berusaha untuk melakukan internalisasi nilai-nilai religious culture kepada mahasiswi yang ada di pesantren (POMASI), sehingga berdampak pada kesolihan sosial yang berawal dari kesalihan-kesalihan ritual budaya keagamaan.

\section{Diskusi dan Pembahasan}

\section{Religious Culture}

Religious Culture adalah (budaya beragama) yang memiliki arti yang sama dengan suasana atau suasana religi keagamaan. Dunia yang mengglobal membawa konsekuensi interaktif persaingan antar dan budaya semakin sengit, sehingga tidak ada tempat untuk menyembunyikan diri, karena itu etos kerja muslim harus mampu mewujudkan isyarat atau ayat-ayat AlQur'an sebagai inspirasi dan motivasi yang luar biasauntuk interaksi, bakan bersaing dengan tujuan atau tema sentral dalam format atau skala global rahmatal lil alamin (Tulungagung et al., 2019). 
Agama ialah sistem symbol, sistem yang berkyakinan, sistem nilai, dan sistem perilaku yang terlembagakan, yang berpusat pada persoalanpersoalan yang dihayati dan yang pling maknawi. Berikut lima macam dimensi keberagamaan. Dimensi keyakinan yang di harapkan, dimana orang beragama bersi keras pada pandangan teologis tertentu akui kebenaran doktrin. Dimensi praktik agama, termasuk perilaku beribadah, ketaatan, dan apa yang orang lakukan untuk menunjukkn sebuah komitmenya terhadap agama masing-masing yang dianutnya. Dimensi pengalaman, dimensi ini mengandung dan peduli ke semua agama mengandung fakta yang diharapkan pastinya, meski tidak benar dikatakan bahwa seorang yang beragama dengan baik, maka suatu waktu akan nencapai pengetahuan subjektif dan langsung mengenai kenyataan di akhir, maka ia akan mencapai dengan kekuatan spiritual (Pranikah et al., 2018).

Dimensi pengetahuan, agama yang mengacu pada harapan ini setidaknya orang yang beragama memiliki sejumlah minimal pengetahuan untuk dapat mencapai dasar-dasar keyakinan, ritus-ritus, kitab suci dan tradisi (budaya). Dimensi pengalaman, mengacu pada dimensi ini identifikasi akibat-akibat keyakinan, keagamaan, praktik, pengalaman, dan pengetahuan seseorang sehari-hari. [14] orang-orang beragama paling tidak memiliki minimal pengetahuan, antara lain dasar tradisi / budaya yang memiliki beberapa fungsi, antara lain, dapat bertindak sebagai wadah ekspresi keagamaan, dan alat pengikat kelompok.[9] Menurut Novan Ardy Wiyani, pendidikan yang berbasis iman dan taqwa. Pembentukan budaya religious culture (budaya agama) dalam lingkungan sekolah yang mendukung kualitas keimanan dan ketaqwaan guru beserta para didik-didiknya (Putra, 2017).

\section{Kesholehan Sosial Remaja Di Pesantren}

Salah satu metode yang di anggap tepat agar remaja memiliki kesalehan ritual dan sosial adalah melalui penanaman nilai-nilai pendidikan agama. Pendidikan agama di harapkan mampu meningkatkan tercapainya potensi spiritual serta membentuk siswa agar menjadi manusia yang beriman dan bertaqwa kepada tuhan yang maha esa dab berakhlak mulia. Beriman pada tuhan yang maha esa berarti memiliki kesalehan ritual sedangkan berakhlak mulia berarti memiliki kesalehan sosial, yang mencakup etika, budi pekerti, dan moral, sebagai perwujudan dari pendidikan agama. Manusia yang 
memiliki kesalehan ritual maupun sosial yang baik pada akhirnya akan membentuk watak dan perilaku keagamaan dan kehidupan sehari-hari (Qur et al., 2020).

Salah satu fungsi dan tujuan pendidikan di sekolah adalah mengembangkan keagamaan siswa agar memiliki kebiasaan berperilaku keagamaan yang mencangkup dimensi iman (berupa keyakinan, sikap, dan perasaan) serta dimensi amal berupa ibadah muamalah, oleh karna itu, pendidikan agama berkisar pada dua dimensi kehidupan manusia yakni penanaman rasa taqwa kepada tuhan dan pengembangan rasa kemanusiaan kepada sesama. Pendidikan agama yang di ajarkan di sekolah sudah seharusnya selaras dengan regulasi pendidikan sehingga mampu mengantarkan siswa menjadi manusia yang beriman dan bertaqwa kepada tuhan yang maha esa. Dalam kerangka itu, pendidikan agama seyokyanya menjadi siswa berperilaku terpuji, baik menyangkut hubungan vertikan dengan tuhan maupun hubungan horizontal dengan sesama manusia (Karakter, 2013).

Saat ini masih terjadi di kotomi antara kesalehan ritual yang bersifat individual dan kesalehan sosial. Banyak orang beragama yang secara individu saleh namun tidak secara soaial, banyak orang yang rajin solat, namun tidak peka dengan kerusakan alam, banayak orang yang sering pergi haji dan umroh, namun tidak peka dengan kemiskinan yang melanda orang lain. Hal ini tentu saja membuat sikap saleh itu kurang sempurna. Idealnya kesalehan individual dan kesalehan sosial ibarat dua sisi mata uang yang tidak bisa di pisahkan. Secara idealitas semakin tinggi kesalehan ritual seseorang akan berdampak dengah kesalehan sosialnya (Tulungagung et al., 2019).

Seorang remaja harus mampu membina moral yang ada dalam dirinya melalui pengalaman yang yang dimilikinya pada masa kanak-kanak sampai dengan mencapai kematangan baik dalam segi jasmani, rohani, social dan ekonomi. Usia remaja pada hakekatnya adalah masa menemukan jati diri, meneliti sikap hidup yang lama dan mencoba-coba yang baru untuk menjadi pribadi yang dewasa.

Perilaku beragama adalah segala aktifitas yang merupakan menisfestasi dari adanya hubungan manusia dengan tuhannya yang terwujud dalam sikap batinnya yang taat menjalankan perintahnya dan menjauhi larangannya serta tampkan ibadahnya sehari-hari. Perilaku keagamaan ini berujung pada dua 
buah kesaleha yaitu kesalehan ritual dan kesalehan sosial. Tindakan yang berhubungan dengan pribadi manusia yang didasarkan dapa konsep keimanan kepada tuhannya merupakan kesalehan individual atau ritual. Dimensi-dimensi kesolehan ritual meliputi kepercayaan pribadi terhadap doktrin dan ajaran agama islam yang meliputi keyakinan kepada Allah, malaikat, rasul, kitab suci, qada' dan qadar serta hari akhir (Ushuluddin et al., 2018).

Kesolehan ritual dan sosial seorang siswa dapat di berntuk dengan memberikan pendiddikan agama di sekolah. Hal ini memacu pendapat zuhairini bahwa pendididkan agama berarti usaha-usaha yang dilakukan secara sadar, terencana, dan prakmatis dalam upaya membantu anak didik supaya mempunyai ilmu pengetahuan agama (Wibowo, 2019). Perbincangan mengenai kesalehan sosial sedang marak terjadi di kalangan kelas menengah muslim indonesia. Secara sederhana, pengertian kesalehen sosial dimaknai sebagai ekspresi dan peraktik orang-orang islam yang peduli terhadap nilainilai sosial, seperti halnya menyumbang dana bantuan beruapa infk, sodaqah, maupun amal jariyah, namun cenderung "abai" terhadap ibadah pribadi. Munculnya praktik sosial tersebut merupakan bentuk ekspresi filantropis yang hendak dilakukan kelas menengah muslim indonesia. Adanya pertumbuhan ekonomi tinggi dengan semakin meratanya redisrtibusi pendapatan berkelindan dengan adanya kebutuhan akan donasi social (Falah, 2016).

Islam merupakan agama mayoritas dianut masyarakat Indonesia. dalam skala global, masyarakat islam indonesia merupakan masyarakat islam terbesar di dunia. Sebagai agama yang banyak dianut, Islam tentu tidak bisa diabaikan begitu saja dalam kehidupan sosial masyarakat Dinamika perkembangan agama remaja dipengaruhi oleh beberapa faktor, yaitu: pengaruh Pendidikan atau pengajaran dan berbagai tekana social, termasuk Pendidikan orang tua, tradisi- tradisi social, tekanan lingkungan social yang disepakati liggkungan itu (D. I. L. Pendidikan, n.d.). Berbagai pengalaman yang membentuk sikap keagamaan, terutama pengalaman-pengalaman mengenai keindahan, keselarasan, kebaikan di dunia ini, konflik moral dan pengalaman emosi beragama. Kebutuhan yang belum terpenuhi terutama kebutuhan keamanan, cinta kasih, harga diri serta ancaman kematian. 
Adapun pemaknaan kesalehan sosial sendiri lebih pada strategi membangun relasi harmonis dengan sesama umat manusia lainnya tanpa harus meninggalkan jati diri umat islam itu sendiri. Islam wasataniyyah sebenarnya adalah ide klasik yang kemudian di revitalisasi kembali dalam diskursus sinergis antara nilai islam dan pembangunan umat. Titik tekan utama untuk mensinergiskan kedua entitas itu terletak pada pemahaman islam yang sifatnya eksoterik, namun tetap syar'i. Budaya-budaya Islam yang kemudian di gali kembali seperti halnya tasamuh, sawazun, ta'adul kemudisn ditetapkan sebagai nilai penting dalam membangun dan meperkuat kembali nilai-nilai islam dan juga masyarakat Islam (Suyatno, 2013).

Pesantren sebagai Lembaga Pendidikan Islam, memiliki peran penting untuk menanamkan nilai-nilai budaya keagamaan (religious culture) yang Islamis tak terkecuali kesolihan sosial remaja muslim agar berkatakter sesuai dengan tuntunan agama Islam yang rahmatal lil'alamin. Kehadiran pondok pesantren justru menjadi magnet tersendiri dalam menciptakan kabudayaa dan praktik keagamaan serta Muslim dan peradaban Islam yang berkualitas. Pesantren sebagai wadah untuk menempa ilmu. Output pesantren (alumni) diharapkan memiliki kesalihan-kesalihan termasuk kesolihan sosial yang bermula dari pembiasaan kesalihan ritual-ritual kegamaan yang kokoh, jiwa kemandirian dan kepribadian, perilaku dan karakter yang mulia. Hal inilah yang menjadi dan membedakan pesantren dengan Pendidikan islam pada umumnya (Qodriyah \& Bz, 2020).

Di pesantren ditanamkan amaliyah dan karakter keagamaan yang kuat seperti: kesederhanaan, keikhlasan, kemandirian, ukhwah Islamiyah serta kebebasan berkreativitas dalam bingkai keislaman bahkan kelndonesian sebagai jati diri bangsa berkeagamaan. Oleh karena itu penanaman dan penguatan pendidikan karakter Islam ke Indonesian di pesantren sangatlah penting. Islam ke-Indonesian yang dimaksud adalah Islam Wasathiyah (Niam, 2019).

Berbicara pesantren dan konsep Islam wasathiyah, yang berbasiskan pada nilai tasamuh, tawazun, ta'adul, yang berlandaskan pada Ahlussunnah wal jamaah. Dengan kata lain, Islam wasatiyyah berupaya untuk menjadikan Islam rahmatal lil 'alamin yang tidak hanya berbasis pada agama saja namun juga sudah berwujud sistem nilai dan norma. Nilai wasathiyah tersebut diharapkan 
menjadi ciri has santri dalam nalar berfikir mereka untuk mengahadapi dan menyikapi persoalan-persoalan atau masalah-masalah yang mereka hadapi.

\section{Gambaran Kegiatan}

Kegiatan pengabdian kepada masyarakat (PKM) di Pesantren Nurul Jadid yang bertempat di asrama mahasiswi (POMASI) Universitas Nurul Jadid dilakukan dengan model pendampingan keagamaan dengan pembiasaan Nilai-nilai Budaya keagamaan mahasiswa yang ada di asrama mahasiswi. Pendampingan budaya dan ritual keagamaan ini dikemas dalam kegiatan rohani sehat milleneal. Adapun secara rinci pelaksanaan kegiatan pengabdian masyarakat ini dapat dijelaskan betrikut ini.

\section{Manfaat Kegiatan}

Manfaat dari kegiatan penyuluhan keagamaan melalui pengajian Jum'at Subuh di masjid agung Ar Raudlah adalah sebagai berikut; memberikan tambahan ilmu agama Islam kepada peserta pengajian guna peningkatan keimanan dan ketakwaan kepada Allah SWT, meningkatkan rasa persaudaraan sesama umat Islam (ukhuwah Islamiyah) dikalangan anggota pengajian Jum'at Subuh di masjid agung Ar Raudlah Kraksaan Probolinggo, dan meningkatkan solidaritas sesama anggota pengajian Jum'at Subuh.

\section{Waktu Pelaksanaan Kegiatan}

Kegiatan pendampingan pembiasaan budaya keagamaan melalui kegiatan DITABERHAMAN (Diba'iyah, Tahlil, Berzanji, Hataman dan Manaqib) dilaksanakan pada senin malam selasa setelah shalat Isya' di asrama Mahasiswi (POMASI) pondok pesantren Nurul Jadid paiton Probolinggo. dengan durasi waktu 90 menit, dimulai dari jam 19.00-21.00 WIB dan dijadwal secara bergantian setiap minggunya dalam setiap bulannya. Dengan jadwal yang sudah di sepakati pada kegiatan ini yang meminpin pembacaan kagiatan adalah teman sebaya mahasiswa dengan orang yang berbeda setiap pelaksanaan kegiatan, agar memiliki pengalaman dan kesempatan yang sama semua mahasiswa sesuai dengan jadwal yang telah dibuat oleh pengurus asrama pondok mahasiswi pesantren Nurul Jadid Paiton probolinggo. 


\section{Metode Pelaksanaan Kegiatan}

Pelaksanaan kegiatan pendampingan pembiasaan budaya keagamaan melalui kegiatan DITABERHAMAN di asrama mahasiswi (POMASI) Pondok pesantren Nurul Jadid Paiton Probolinggo memakai metode Peer Teaching dan dialog, dimana teman sebaya yang menjadi pemimpin pembacaan dan diselingi dengan menyampaikan isi atau kandungan apa yang dibaca pada kegiatan tersebut. Model komunikasi yang digunakan adalah komunikasi dua arah (twoway communication), artinya salah satu dari teman sebaya sebagai pemimpin pembacaan dan menyampaikan isi ataukandungan dan manfaat dari kegiatan yang mereka laksanakan, sementara yang lain sebagai anggota untuk mengikuti bacaan dan mendengarkan kegiatan secara bersam-sama.

\section{Materi Kegiatan}

Macam-macam kegiatan dalam pendampingan pembiasaan religious culture ini adalah melalui kegiatan DITABERHAMAN pada malam selasa dimulai dari jam 19.30-21.00 yang dilaksanakan di asrama mahasiswi (POMASI) Pondok pesantren Nurul Jadid Paiton Probolinggo tersusun sebagai berikut:

1. Malam selasa Minngu pertama pada setiap bulannya adalah pelaksanaan kegiatan Diba'iyah

2. Malam selasa minggu kedua adalah pelaksanan kegiatan Tahlil Bersama

3. Malam Selasa minggu keiga adalah pelasnaan kegiatan berzanji

4. Malam selasa minggu ke empat adalah pelaksanaan kegiatan Manaqib

5. Malam selasa adalah pelaksanaan hataman al-qur'an. Pelasnaan hataman qur'an dilaksanakan dengan mengklasifikasi 30 anak yang tidak berhalagan membaca al-Qur'an). Satiap anak mendapat satu juz al-qur'an untuk dibaca, kemudian do'a khotmil Bersama-sama yang di pimpin oleh pengurus senior.

\section{Hasil Kegiatan}

Hasil kegiatan pengabdian dan pendampingan budaya keagamaan (religious culture) dalan kontsruksi kesalihan sosial remaja di pesantren 
melalui kegiatan rohani sehat millenial "DITABERHAMAN" masiswi Universiras Nurul jadid di asrama Pondok mahasoswi (POMASI) Pesan Nurul Jadid Paiton Probolinggo adalah meningkatnya wawasan ilmu agama Islam dan meningkatnya pengamalan praktek budaya keagamaan ditandai dengan terbangunnya kesalihan soasial yang di awali dengan kesalihan ritual budaya keagaman dan di harapkan Perilaku budaya keagamaan ini berujung pada dua buah kesaleha yaitu kesalehan ritual dan kesalehan sosial.

\section{Dinamika Keilmuan}

Setelah kegiataan pengabdian masyarakat dijalankan, bermula dari kesalihan ritual santri maka kesalihan sosial santri akan terkonstruk. Dinamika keilmuan remaja di pesantren (mahasiswi) di asrama POMASI tentang risalah Nabi muhammad dan menjadi meningkat yang kemudian mengikuti sunnah nabi Muhammad dalam membangun kesolihan sosial mereka, mereka mulai menyadari bahwa umat Islam. Perilaku budaya keagamaan ini berujung pada dua buah kesaleha yaitu kesalehan ritual dan kesalehan sosial. Tindakan yang berhubungan dengan pribadi manusia yang didasarkan dapa konsep keimanan kepada tuhannya merupakan kesalehan individual atau ritual. Dimensi-dimensi kesolehan ritual meliputi kepercayaan pribadi terhadap doktrin dan ajaran agama islam

\section{Teori yang Dihasilkan dari Pendampingan}

Teori yang dihasilkan dari pelaksanaan kegiatan pengabdian melalui pendampingan, dengan metode action research ini adalah menyempurnaan teori strategi internalisasi nilai agama Islam yang dikemukakan oleh Muhaimin, yang menyatakan bahwa strategi internalisasi yang harus digunakan meliputi 3 strategi yakni (1) Power strategy, yakni strategi pembudayaan agama dengan cara menggunakan kekuasaan atau melalui people's power, dengan segala kekuasaannya sangat dominan dalam melakukan perubahan; (2) persuasive strategy, yang dijalankan lewat pembentukan opini dan pandangan masyarakat (3) normative re-educative. Artinya norma yang berlaku di masyarakat termasyarakatkan lewat educasi yang dilaksanakan pesantren, mengganti paradigma berpikir masyarakat yang lama dengan yang baru. Pada strategi pertama tersebut dikembangkan 
melalui pendekatan perintah dan larangan atau reward dan punishment. Sedangkan strategi kedua dan ketiga tersebut dikembangkan melalui pembiasaan, keteladanan, dan pendekatan persuasif atau mengajak pada warganya dengan cara yang halus, dengan memberikan alasan dan prospek baik yang bisa menyakinkan mereka.

\section{Kesimpulan}

Kegiatan pengabdian kepada masyarakat pada remaja santri, diasrama mahasiswi (POMASI) Pondok pesantren Nurul Jadid disimpulkan sebagai berikut: pertama kegiatan Sehat rohani milleneal yang kemudian dibuat akronin "DITABERHAMAN" dapat berjalan sesuai dengan rencana pengabdian yang di lakukan oleh peneliti, setelah dilakukan strategi Pembiasaan (habituasi) nilai-nilai religious culture dalam merekonstruksi kesalihan sosial remaja di pesantren melalui kegiatan rohani sehat milleneal (DITABERHAMAN; Diba'iyah, talil, berzanji, hataman qur'an dan Manaqib dengan menggunakan teknik dan metode Pear teaching. Kedua mahasiswi dipesantren sudah bisa memimpin bacaan DITABERHAMAN serta menghayati isi yang terkandung pada bacaan tersebut, sehingga bermula pada kesolihan ritual yang dilaklasanakan melalui pengabdian ini bisa mengkonstruk kesolihan sosial mereka. Karena meneladani dari sunnah nabi dari apa yang termuat dalam pembacaan risalah Nabawi yang terkandung dalam bacaan diba'iyah dan berzanji, juga meneladani para salafussalih syekh Abdul Qodir Jailani yang terkandung dalam Risalah Manaqib Syaikh Abdul Qodir Jailani.

\section{Daftar Pustaka}

Falah, R. Z. (2016). Membentuk Kesalehan Individual dan Sosial Melalui Konseling Multikultural. 7(1), 163-188.

Karakter, K. P. (2013). Karakteristik Pendidikan Karakter; Menjawab Tantangan Multidimensional Melalui Implementasi Kurikulum 2013. 01(01), 89-101.

Kholid Junaidi. (2016). SISTEM PENDIDIKAN PONDOK PESANTREN DI INDONESIA (Suatu Kajian Sistem Kurikulum di Pondok Pesantren 
Lirboyo). ISTAWA: Jurnal Pendidikan Islam, 2(2), 16. https://core.ac.uk/download/pdf/305069843.pdf

Kunci, K., Religius, N., Kamil, I., Values, R., \& Personality, H. (n.d.). Muh . Khoirul Rifa' $i$ (UIN Sunan Ampel Surabaya ). 116-133.

Mannuhung, S. (2019). Penanggulangan Tingkat Kenakalan Remaja Dengan Bimbingan Agama Islam. 2(1), 9-16.

Niam, Z. W. (2019). Konsep Islam Wasathiyah Sebagai Wujud Islam Rahmatan lil 'alamin: Peran Nu dan Muhammadiyah dalam Mewujudkan Islam Damai di Indonesia. Palita: Journal of Social Religion Research, 4(2), 91106. https://doi.org/10.24256/pal.v4i2.764

Pendidikan, D. I. L. (n.d.). RELIGIOUS CULTURE.

Pendidikan, F. (2015). Filsafat Pendidikan dan. 11(2), 291-312.

Pranikah, S., Kajian, S., Sabarni, S., Hidajat, L. L., Susana, S., H, L. L., Alok, K., \& Barat, A. (2018). ARTIKEL PENELITIAN Peran Nilai Pribadi, Nilai Budaya dan Nilai Religius terhadap Sikap Remaja dengan lawan jenis, yang biasanya diwujudkan dalam Kesehatan Masyarakat Flores-Lembata (Yakkestra ). Kamis, 2 November 2017 lalu, di Hotel Permata Sari, Masyarakat Indonesia memandang seks pranikah sebagai tindakan yang tidak dapat diterima tertentu dan menyerap perilaku dan nilainilai tingkah laku yang diharapkan, di mana dengan nilai laku dalam berbagai macam situasi . 5(2). https://doi.org/10.22146/jkr.37885

Putra, K. S. (2017). Implmentasi Pendidikan Agama Islam Melalui Budaya Religius (Religious Culture) Di Sekolah. Jurnal Kependidikan, 3(2), 1432. https://doi.org/10.24090/jk.v3i2.897

Qodriyah, K., \& Bz, Z. (2020). PENDIDIKAN ISLAM MULTIKULTURAL BERWAWASAN WASATHIYAH: PENGUATAN KARAKTER WASATHIYAH. 04(02), 246-257. https://doi.org/10.33852/jurnalin.v4i2.234

Qur, T. A.-, Studi, M., Sunan, U. I. N., Yogyakrta, K., \& Garwan, M. S. (2020). Konstruksi Identitas Kultural dan Kesalehan Sosial Perempuan Ternate Dalam Pendekatan Sejarah Sosial dan Muhammad Sakti Garwan. 199220. 
Saifuddin, A. (n.d.). EKSISTENSI KURIKULUM PESANTREN DAN KEBIJAKAN PENDIDIKAN Ahmad Saifuddin (Dosen STAI Darussalam Krempyang Nganjuk). 207-234.

Studi, P., Di, K., \& Pesantren, P. (2019). Andragogi : Jurnal IImiah Pendidikan Agama Islam Volume 1 Nomor 2 Tahun 2019 e-ISSN: 2655-948X. 1(November), 39-49.

Suyatno, S. (2013). MULTIKULTURALISME DALAM SISTEM PENDIDIKAN AGAMA ISLAM: Problematika Pendidikan Agama Islam di Sekolah. Addin, 7(1), 81-104.

Tulungagung, I., Mayor, J., No, S., Kedungwaru, K., Tulungagung, K., \& Timur, J. (2019). Paradigma manajemen leader dalam konstruksi kesalehan sosial siswa di ma shofa marwa kabupaten grobogan. 07, 101-124. https://doi.org/10.21274/taalum.2019.7.1.

Ushuluddin, F., Filsafat, D. A. N., \& Ar-raniry, U. I. N. (2018). Kesalehan sosial dalam berpakaian di kalangan remaja putri di kota banda aceh.

Wardi, M. (n.d.). Penerapan Nilai Pendidikan Agama Islam Dalam Perubahan Sosial Remaja.

Wibowo, A. M. (2019). KESALEHAN RITUAL DAN KESALEHAN SOSIAL SISWA MUSLIM SMA RITUAL PIETY AND SOCIAL PIETY OF MOSLEM HIGH SCHOOL STUDENTS IN THE EX SURAKARTA RESIDENCY Pendahuluan. 05(01), 29-43. 


\section{GUYUB}

\section{Journal of Community Engagement}

P-ISSN: 2723-1232

E-ISSN: 2723-1224

GUYUB: Journal of Community Engagement is is a multidisciplinary journal which aims to disseminate the conceptual thoughts and research results in the area of community service. This journal focuses on the main problems of the community engagement areas, such as (1) training, marketing, appropriate technology, design; (2) student community services; (3) community empowerment, social access; (4) education for sustainable development, etc.

GUYUB: Journal of Community Engagement is published three times a year (April, August, December) by Lembaga Penerbitan, Penelitian, dan Pengabdian kepada Masyarakat (LP3M) Universitas Nurul Jadid, Paiton, Probolinggo, Jawa Timur, Indonesia.

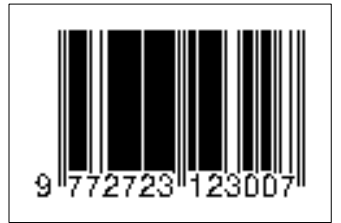

Editorial Office:

GUYUB: Journal of Community Engagement

Lembaga Penerbitan, Penelitian, dan Pengabdian kepada Masyarakat

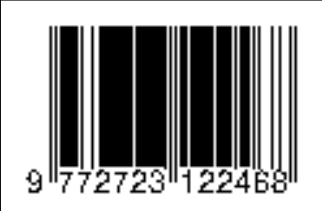

(LP3M) Universitas Nurul Jadid, Probolinggo, Jawa Timur, Indonesia 67291.

Phone: 088830 77077, Hp: 082318007953

Email: jurnal.guyub@gmail.com

Website: https://ejournal.unuja.ac.id/index.php/guyub/index 